\title{
A Simulation-Based Approach for Developing Optimal Calibrations for Engines with Variable Valve Actuation
}

\author{
B. Wu' , Z. Filipi ${ }^{1}$, R. Prucka ${ }^{1}$, D. Kramer ${ }^{2}$ and G. Ohl ${ }^{2}$ \\ 1 University of Michigan, 2031 W. E. Lay Automotive Lab, 1231 Beal Ave., Ann Arbor, Ml 48109-2133, USA \\ 2 DaimlerChrysler Corporation, 800 Chrysler Drive, Auburn Hills, MI 48326-2757, USA \\ e-mail: BW211@daimlerchrysler.com - filipi@umich.edu - rprucka@umich.edu -dmr29@daimlerchrysler.com - glo1@daimlerchrysler.com
}

\begin{abstract}
Résumé - Une approche basée sur la simulation pour le développement de réglages optimaux des moteurs avec système d'actionnement variable de soupape - La technologie d'actionnement variable de soupape (Variable Valve Actuation, VVA) présente un fort potentiel pour augmenter les performances et réduire consommation et pollution. Les avantages du VVA proviennent d'une meilleure aération et de la possibilité de contrôler les résidus internes. Par contre, l'addition de variables de contrôle supplémentaires dans un moteur VVA augmente la complexité du système, ce qui nécessite la mise au point d'une stratégie de contrôle optimale afin d'en tirer tous les bénéfices. L'approche traditionnelle reposant sur l'expérimentation s'avère trop onéreuse dans ce cas du fait de l'augmentation exponentielle du nombre de tests. Ce projet propose comme alternative de définir le réglage des soupapes comme un problème d'optimisation. Il identifie les simulations nécessaires au développement d'une méthode générique capable d'intégrer un nombre croissant de degrés de liberté afin de développer un outil de grande fidélité pour la prédiction des effets de différents dispositifs. Puisque la résolution d'un problème d'optimisation requiert l'évaluation de centaines de fonctions, l'utilisation directe d'une simulation hautefidélité demande des temps de calculs beaucoup trop longs. En remplacement, un réseau artificiel de neurones est entraîné avec des résultats de simulation haute-fidélité et utilisé pour représenter la réponse du moteur à différentes combinaisons de variables de contrôle, et ce avec des temps de calcul beaucoup plus courts. Cet article décrit une méthode basée sur la simulation, apporte des détails sur les techniques de modélisation haute-fidélité et démontre une application à un prototype de moteur à essence à quatre cylindres et double arbre à cames indépendant.
\end{abstract}

\footnotetext{
Abstract - A Simulation-Based Approach for Developing Optimal Calibrations for Engines with Variable Valve Actuation - Variable Valve Actuation (VVA) technology provides high potential for achieving improved performance, fuel economy and pollutant reduction. Benefits of VVA stem from better breathing and the ability to control internal residual. However, additional independent control variables in a VVA engine increase the complexity of the system, and achieving its full benefit depends critically on devising an optimum control strategy. The traditional approach relying on experimentation is in this case prohibitively costly, since the number of tests increases exponentially. Instead, this work formulates the task of defining actuator set-points as an optimization problem. It identifies simulation needs for supporting development of a generic methodology, capable of handling increased number of degrees of freedom. A high-fidelity tool predicts effects of various devices being considered. Since solving
} 


\begin{abstract}
an optimization problem requires hundreds of function evaluations, direct use of the high-fidelity simulation leads to unacceptably long computational times. Instead, the Artificial Neural Networks $(A N N)$ are trained with high-fidelity simulation results and used to represent engine's response to different control variable combinations with greatly reduced computational time. The paper describes a comprehensive simulation-based methodology, provides details of high-fidelity and surrogate modeling techniques, and then demonstrates application on a prototype four-cylinder spark-ignition engine with dual independent cam-phasers.
\end{abstract}

\section{INTRODUCTION}

Passenger car engines experience a very wide range of operating conditions. Flexible systems have thus become increasingly attractive as means of achieving optimal engine-in-vehicle operation. Advanced Variable Valve Actuation (VVA) technologies are particularly promising in saving fuel, reducing emissions and increasing Spark-Ignition (SI) engine output [1-5]. Among various VVA options, cam-phasing is gaining broad acceptance, due to its ease of implementation and tangible advantages over conventional fixed-cam engines [611]. The continuous, dual independent cam-phasing, i.e. independent phasing of intake and exhaust cams - offers significant flexibility in optimizing engine breathing and internal residual gas fraction, while preserving the relative simplicity of Variable Valve Timing (VVT) concept.

The extra flexibility enabled with intake and exhaust camphasers increases the overall system complexity by introducing more degrees of freedom. For any arbitrary operating point, the set-points of intake and exhaust cam-phasers need to be defined during calibration development. This creates a challenge for the traditional calibration approach relying on experimentation in the dynamometer test-cell. The increase in the number of independent variables leads to an exponential increase of the number of tests required. This easily becomes unmanageable and prohibitive in terms of cost and development time. Novel approaches are needed for addressing the problem of set-point calibration in high degree-offreedom (DOF) engines. Hence, attempts have been made to reduce the effort and address cam-phasing optimization using computer simulations and design-of-experiments approaches [12-17]. However, these approaches are suitable only for systems with a moderate increase of DOF. This work presents development of a comprehensive methodology utilizing advanced modeling techniques and an optimization framework to determine the best combination of actuator set-points for a given objective. Relying on predictive models and multi-variable optimization makes the methodology generic, as it allows handling any number of independent variables within reasonable limits. The methodology is demonstrated through a case study of an SI engine with two additional DOF enabled by dual-independent cam phasing.
A high-fidelity engine simulation is used to characterize the effects of cam-phasing on engine performance, fuel consumption and, to some degree, emissions. After calibrating the model constants with a limited number of experimental data, the simulation tool is able to predict engine behavior with sufficient fidelity for generating a robust calibration [18]. The predictiveness of physics-based models used in a high-fidelity simulation allows investigations of new system configurations, even those that have not been built yet. Given the fact that running a high-fidelity simulation takes a significant amount of computation time and solving an optimization problem requires hundreds of function evaluations, a faster engine model is required to enable optimizations at many operating points. Artificial Neural Networks (ANN) [19] are very computationally efficient, and are therefore considered as fast surrogate models suitable for optimization exercises. Previous applications of ANNs in the automotive field encourage their use here. He et al. [20, 21] have demonstrated ANN's capability of modeling a turbo-charged diesel engine. Brahma et al. [22] used the ANN models to optimize control variables of the diesel engine, although with some challenges regarding noise in optimization results. On-Board Diagnostics (OBD) [23, 24] and Hardware-in-the-Loop (HIL) simulation [25-27] exploited ANNs computational efficiency. Using ANN's for estimating mass air flow rate through the VVT engine has been demonstrated by Wu et al. in [28].

With the goal of either maximizing performance or minimizing fuel consumption, the set-point calibration is formulated and solved as a series of optimization problems with objectives and constraints defined at individual operating points. Constraints include functional limits of cam phasers and critical engine output variables, such as exhaust temperature or knock intensity. Selection of independent variables and constraints changes depending on the particular task, e.g. $F / A$ ratio is an independent variable when maximizing WOT performance, while stoichiometric mixture composition becomes a prescribed parameter when minimizing fuel consumption at part load. The optimality of intake and exhaust cam phasing determined using the proposed simulation-based methodology is verified with experiments in the test cell. Potential challenges related to practical implementation, such 
as smoothing of rapid high-amplitude excursions of optimized cam-phaser positions, and limiting $\mathrm{NO} x$ emissions over a set of representative driving cycles, are addressed in the post-optimality study.

The paper is organized as follows. The next section describes the optimization framework and outlines the complete methodology. Then, the high-fidelity simulation tool is introduced. The effects of cam-phasing on gas exchange and overall sensitivity of engine output to valve timing is analyzed in a pre-optimality study. This is followed by a procedure for building ANN surrogate models. Next, two optimization problems are formulated with different objectives and constraints: maximizing engine torque output is the objective at wide open throttle, while minimizing fuel consumption becomes an objective at part load. Maps of optimal camshaft positions are generated by solving the optimization problem using ANN surrogate models. Benefits of optimizing valve timing are quantified through comparisons with baseline fixed-cam engine. Finally, practical implementation issues are considered, including a technique for including emissions target into the optimization formulation and ensuring reduction of total emissions over a selected driving cycle. The paper ends with summary and conclusions.

\section{OVERALL METHODOLOGY - OPTIMIZATION FRAMEWORK}

The overall methodology relies on a basic premise that a multi-variable optimization algorithm can be utilized to determine the best combination of actuator set-points for any operating condition. Simulation tools having appropriate level of fidelity are an essential part of the methodology. A high-fidelity, predictive tool is necessary for pre-optimality studies and for generating data required for building fast models. A fast model is needed for enabling computationally intensive optimization runs, since solving a single optimization problem might require hundreds of function evaluations. In this work we propose neural network based fast surrogate models rather than a combination of empirical models or

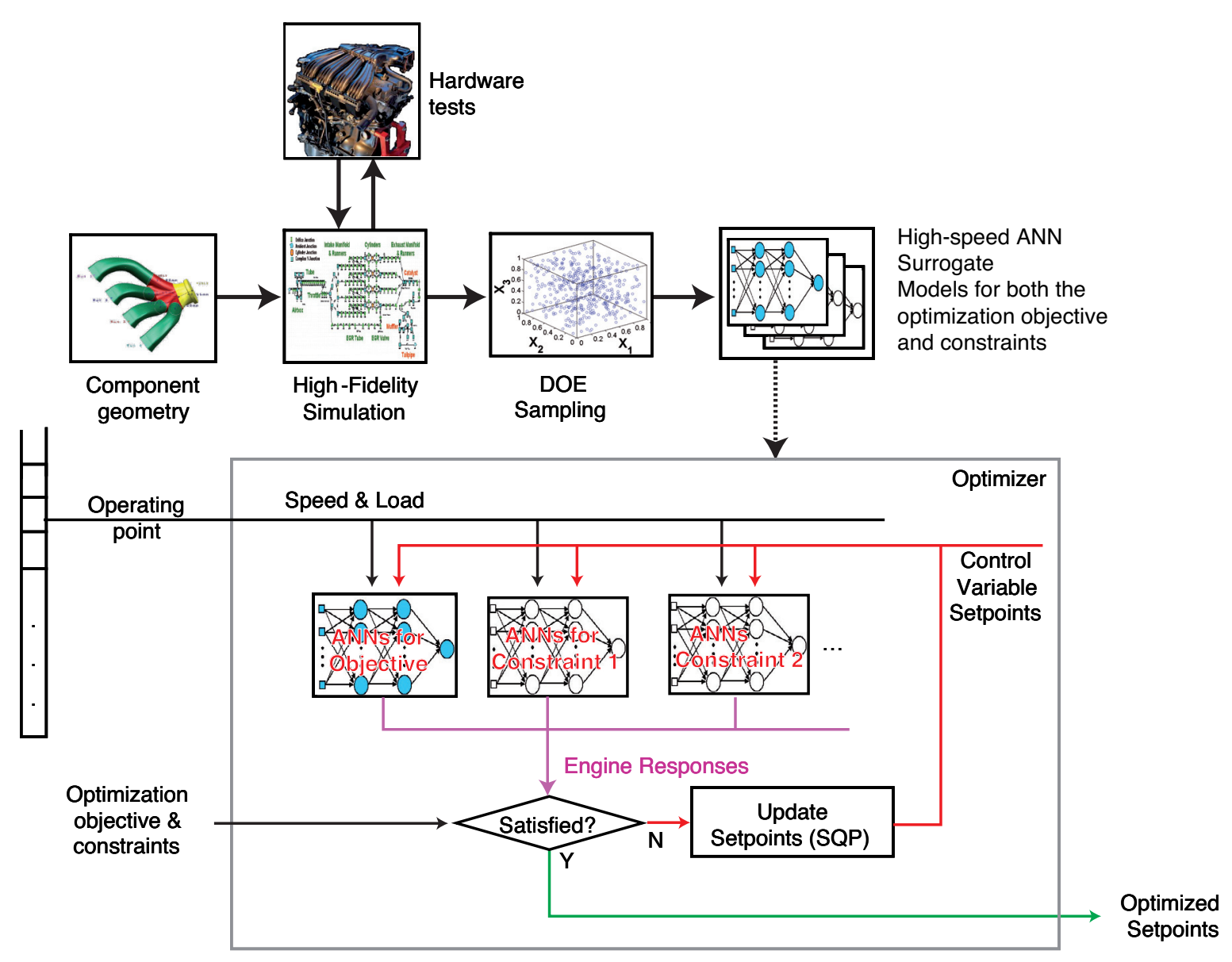

Figure 1

Framework for calibrating independent control variables in high-degree-of-freedom engines. 
curve-fits. The motivation stems from the assessment that input-output relationships in high degree-of-freedom engines are too complex to be easily captured by a simplified empirical model. In contrast, ANNs have been proven to be universal function approximators [29, 30], capable of representing complex mapping relationship between multiple inputs and outputs.

A schematic illustrating the optimization framework and overall methodology is given in Figure 1. The upper branch in Figure 1 shows the steps required to build ANN surrogate models. The high-fidelity simulation replaces experimentation that used to be a corner-stone of traditional calibration methodologies. The experiments are still required, but only to provide sufficient data for validating a baseline high fidelity simulation. A validated model can then be modified and used to explore design options that might not exist in hardware. As an example, an engineer might desire investigating the effects of valve lift using a simulation tool adapted from a baseline model that has already been validated on an engine with cam-phasing. In addition, a simulation can characterize engine behavior under different environmental conditions, such as high altitude or extreme temperatures if a test cell with full climate control is not available. Even if the hardware exists, a simulation-based approach offers significantly reduced time and cost provided that up-front modeling effort is done. Design of Experiments (DOE) is used to additionally streamline the process of creating a data base for training ANNs. A set of ANN surrogate models is generated to represent the engine's response to different combinations of independent control variables. Each ANN represents one engine variable that is included in the optimization objectives or constraints. The optimization objective function and constraints can change depending on operating conditions. As an example, maximum output is an obvious objective of optimization at wide open throttle, while $F / A$ ratio and emissions

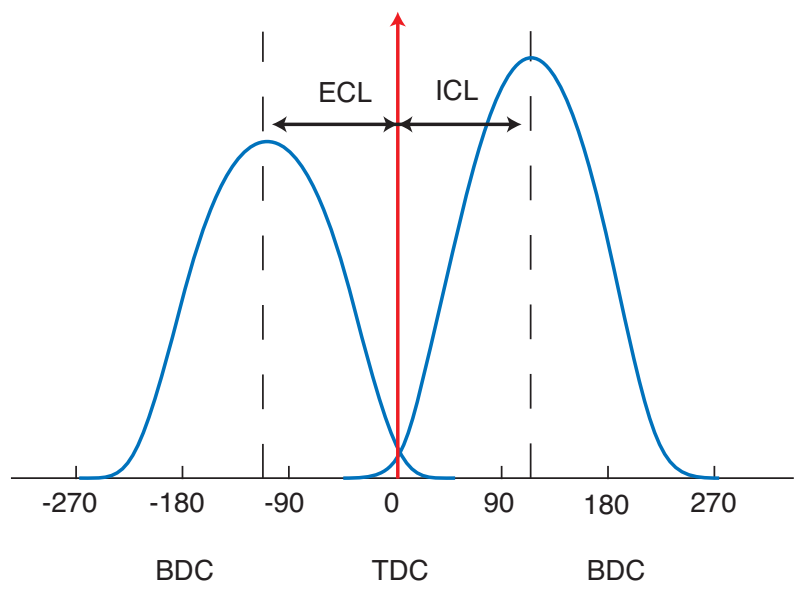

Figure 2

Defining intake and exhaust camshaft phasing with positions of their respective centerlines. can be allowed to vary within certain limits. In contrast, maximizing engine efficiency is the objective of the part load optimization, while preserving a stoichiometric $F / A$ ratio, staying within prescribed exhaust temperature, avoiding misfires or excessive knock, and meeting emissions constraints. It is important to note that there are no apparent limits in the number of independent variables or the formulation of the optimization objective function. Hence, the methodology is generic and, while it will be demonstrated here through a case study of the SI engine with dual-independent cam phasing, it can easily be applied to very different engine or powertrain systems with more degrees of freedom.

\section{ENGINE SPECIFICATIONS AND EXPERIMENTAL SETUP}

The engine used in this study is a production-style 2.4 liter, in-line four cylinder dual overhead camshaft (DOHC) engine manufactured by DaimlerChrysler Corp. Each cylinder has two intake valves and two exhaust valves. The engine was originally designed as a conventional fixed-cam engine. However, the prototype VVT version is equipped with intake and exhaust cam-phasers. Intake and exhaust camshaft positions are independently controlled with vane type hydraulic actuators. Cam lobe profiles, cylinder head and pistons, were not redesigned for VVT operation. Therefore, demonstrating or evaluating the ultimate potential of VVT is not the intention of this study; rather the focus is on the methodology for maximizing torque output or efficiency of a given configuration. The main engine specifications are listed in Table 1.

The phasing of camshafts is described with the Intake Centerline Location (ICL) and Exhaust Centerline Location $(E C L)$. As shown in Figure 2, ICL is defined as the crankangle interval between the top dead center (TDC) and the centerline of intake camshaft lobe; and ECL is defined as the crank-angle interval between TDC and the centerline of exhaust camshaft lobe. The default camshaft positions in the fixed-cam baseline engine are: $I C L_{0}=115$ degrees ATDC and $E C L_{0}=111$ degrees BTDC. The range of varying camphasing with a prototype VVT system is \pm 15 degrees for both intake and exhaust.

The prototype VVT $2.4 \mathrm{~L}$ engine is setup for testing in the University of Michigan W. E. Lay Automotive Laboratory. The engine is coupled to an electric DC dynamometer and instrumented for detailed diagnostics of in-cylinder processes and engine system variables. In particular, cylinder pressure is measured with a Kistler 6125B piezoelectric sensor mounted flush with the combustion chamber wall. Intake and exhaust manifold pressures are measured with piezo-resistive transducers Kistler 4045A2, and a cooling adapter is used to protect the transducer from overheating on the exhaust side. Pressure signals are sampled with one crank angle degree resolution using a VXI-bus data acquisition system with 16-bit 


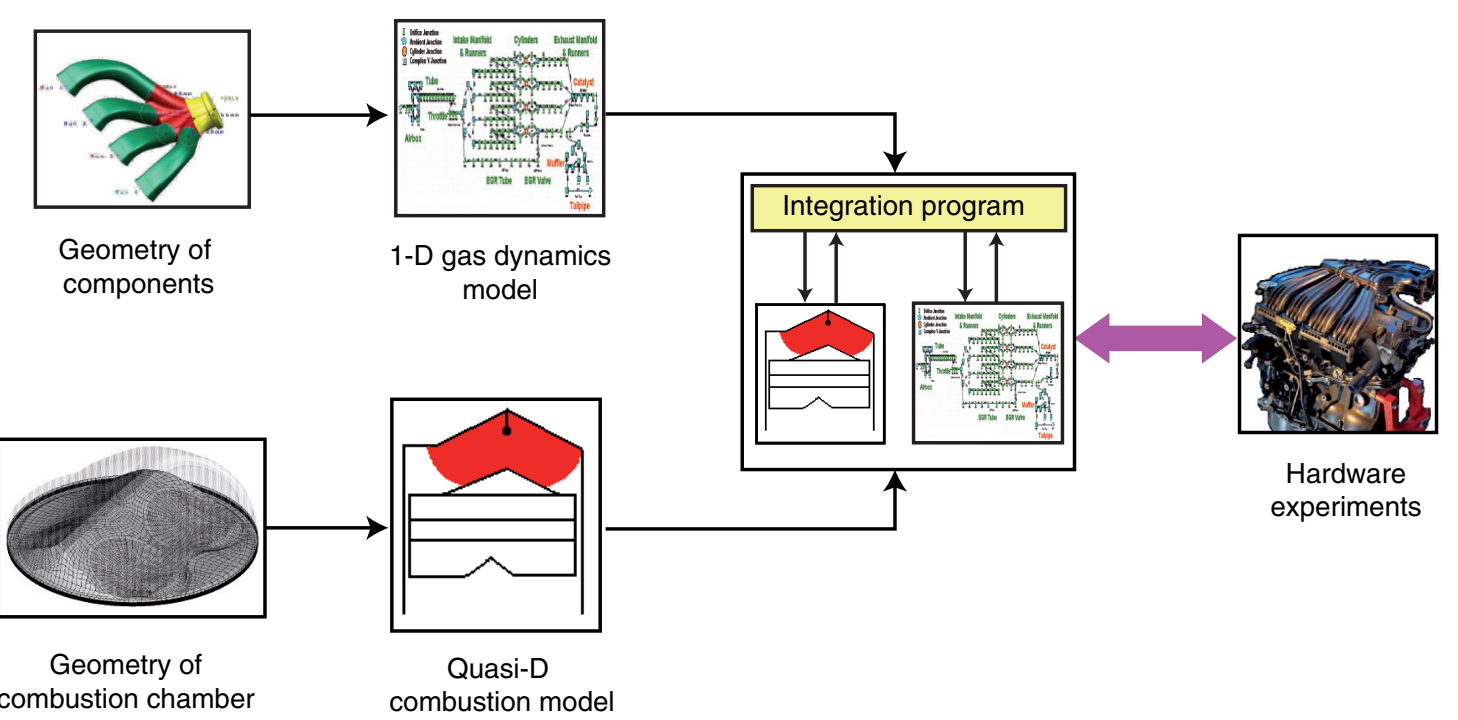

Figure 3

Co-simulation methodology for generating a high-fidelity tool.

vertical resolution. Other signals such as intake air flow rate, air/fuel ratio, intake air and coolant temperatures are recorded using a separate data acquisition system sampling at $10 \mathrm{~Hz}$.

TABLE 1

Specifications of the $2.4 \mathrm{~L} \mathrm{VVT}$ engine

\begin{tabular}{lc}
\hline Displacement & 2.4 liters \\
\hline Bore/Stroke & $87.5 / 101.0 \mathrm{~mm}$ \\
\hline Compression Ratio & $9.4: 1$ \\
\hline Max. Intake Valve Lift & $8.25 \mathrm{~mm}$ \\
\hline Max. Exhaust Valve Lift & $6.52 \mathrm{~mm}$ \\
\hline $\begin{array}{l}\text { Default Intake Valve Timing } \\
\text { Close/Open/ Centerline }\end{array}$ & $51^{\circ} \mathrm{ABDC} / 1^{\circ} \mathrm{BTDC} / 115^{\circ} \mathrm{ATDC}$ \\
\hline $\begin{array}{l}\text { Default Exhaust Valve Timing } \\
\text { Close/Open/ Centerline }\end{array}$ & $9^{\circ} \mathrm{ATDC} / 51^{\circ} \mathrm{BBDC} / 111^{\circ} \mathrm{BTDC}$ \\
\hline Default Valve Overlap & $10^{\circ} @ 0.5 \mathrm{~mm}$ lift \\
\hline Allowed Intake Cam-phasing Range & $\pm 15^{\circ} \mathrm{Crank}$ Angle \\
\hline Allowed Exhaust Cam-phasing Range & $\pm 15^{\circ}$ Crank Angle \\
\hline
\end{tabular}

\section{HIGH-FIDELITY SIMULATION TOOL}

The effects of cam-phasing on engine performance stem primarily from variations of the engine gas exchange process. Valve opening/closing affect gas dynamics and determine the amount of trapped fresh charge at the end of intake process. In addition, large variations of valve events may cause significant variations of turbulence levels and internal residual in the cylinder. This in turn will affect burn rates and emission formation during a particular cycle. Consequently, a truly predictive simulation tools needs to be able to represent these phenomena and capture their effect on engine output. Hence, a high-fidelity simulation tool is developed using a co-simulation approach that integrates a one-dimensional gas dynamics model and a quasi-dimensional combustion model - see illustration in Figure 3. The strength of the commercial code Ricardo WAVE ${ }^{\circledR}$ in gas dynamics modeling is combined with the strength of the quasi-dimensional Spark Ignition Simulation (SIS) in combustion modeling to produce a desired level of fidelity.

WAVE [32] has been widely used and validated for engine performance predictions [33-35]. In this study, the simulation includes the entire flow path comprised of the air-box (filter), intake manifold/runners, intake valves/ports, cylinder block, exhaust valves/ports, exhaust manifold/runners, catalyst, muffler/resonator and a tail-pipe. SIS is a research code that has been refined over time and used routinely at the University of Michigan for a variety of simulation studies [36]. In its various evolutions, the simulation has been used by Filipi et al. [36] for 2- and 4-valve SI engine turbocharger matching studies, in valve event optimization in [37], and for optimizing stroke-to-bore ratio for SI engine deign [38]. The combustion sub-model is based on the 
turbulent flame entrainment model proposed by Tabaczynski [39] and further refined by Poulos and Heywood [40]. The entrainment rate is a function of the instantaneous flame front area, charge density, turbulence intensity and laminar flame speed. Calibration of the combustion model amounts to adjustments of two constants, a dissipation constant in the turbulence model and a constant in the heat transfer correlation [36]. Physics-based models of important phenomena ensure validity of the simulation across the wide operating range. Variations of flow parameters with VVT are captured with the turbulence intensity term. The laminar flame speed term accounts for the effect of fuel/air ratio and residual, which is particularly important in the case of potentially increased overlap leading to large quantities of residual. The formation of NO is governed by extended Zeldovich mechanisms, a practice commonly used in engine cycle simulations $[36,40,46]$. In order to enable considering knock as a constraint, an autoignition model is utilized for predicting knock intensity [41]. The knock model is calibrated based on test cell experiments to ensure its accuracy in capturing behavior of the $2.4 \mathrm{~L}$ engine.

The WAVE and SIS models are coupled at intake and exhaust valves as interfaces. A top level program is developed in C++ to integrate the WAVE and SIS models by feeding WAVE results of valve mass flow rates to SIS, and SIS results for burning rate back to WAVE. Limited experimental data are acquired in the test cell to identify model coefficients such as turbulence dissipation constant, heat transfer correlation coefficient, and engine friction model coefficients. Previous studies have demonstrated that the highfidelity simulation tool is capable of capturing air flow rate accurately $[28,42]$.

Simulation predictiveness is illustrated in Figure 4 and Figure 5. The comparison between predicted and measured engine peak torque as a function of exhaust cam phasing demonstrates the ability of the code to accurately predict the behavior of the complete engine system (see Fig. 4). Graphs in Figures $5 \mathrm{a}$ and $\mathrm{b}$ show details of the in-cylinder process and demonstrate the effect of exhaust valve timing on gas exchange. The relatively low speed (2000 rpm) and low load $(35 \mathrm{~N}-\mathrm{m})$ represents conditions where substantial efficiency improvements can be expected from improved valve timing. The spark timing is set to maximum brake torque (MBT) timing. The late exhaust valve opening (EVO) prolongs the expansion stroke, while late exhaust valve closing (EVC) leads to higher intake manifold pressure due to large valve overlap and residual backflow. Both are favorable for increasing engine efficiency at a given level of output torque. Comparing the high-fidelity predictions shown in Figure 5a and experimental measurements shown in Figure 5b confirms the ability of the physics-based models to precisely capture the effects of valve timing on gas exchange and incylinder processes.

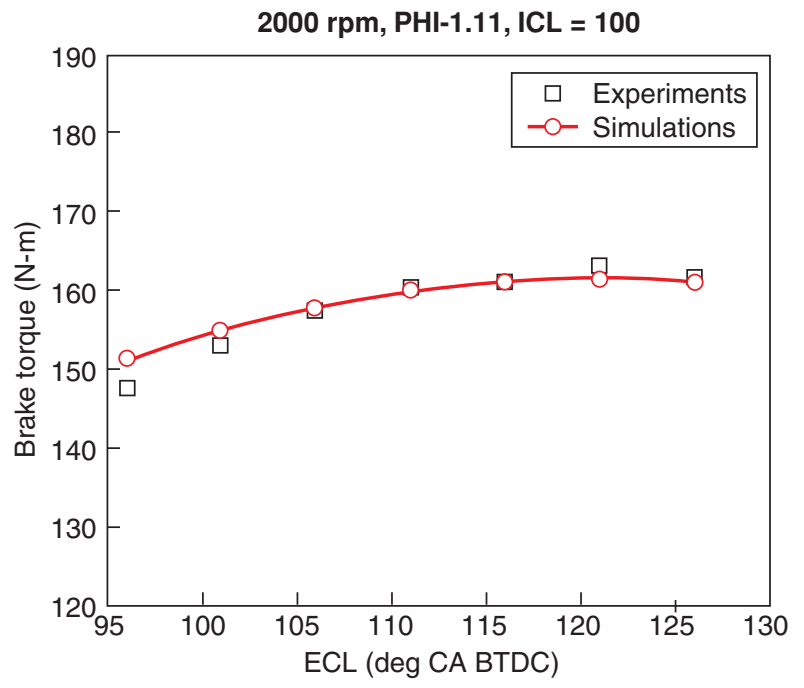

Figure 4

Comparison of predicted and measured engine torque as a function of exhaust cam phasing.

\section{PRE-OPTIMALITY STUDIES - ENGINE SENSITIVITY TO CAM PHASING}

The effort and cost associated with development of the highfidelity code is more than offset by savings in the subsequent optimization process, as well as by its ability to provide a wealth of information beyond what the experimental setup can deliver. For example, internal EGR is hard to measure directly, yet it plays a critical role in VVT engine's performance, fuel economy and NOx emissions. The high-fidelity code is utilized to generate insight about engine sensitivity to main control/operating parameters prior to commencing optimization runs. The pre-optimality results are used as benchmarks for evaluating the behavior of ANN surrogate models described in the next section. In addition, the information will be useful for subsequent interpretation of optimization results. Due to the limited length of the paper, this section only briefly highlights some of the findings.

Figure 6 illustrates variations of engine maximum torque as a function of intake and exhaust cam phasing. Not unexpectedly, the sensitivity to variations of intake cam phasing is much greater. The torque production is directly correlated with air flow rate trend. Detailed analysis of intake valve flow rates revealed that advancing intake timing at low engine speed traps more air in the cylinder since less fresh charge is pushed back before intake valve closes (IVC). Valve overlap and reverse flows during that period were found to be less important at WOT conditions. Lower sensitivity of maximum torque to variations of $E C L$ means that it will be harder to pinpoint the 

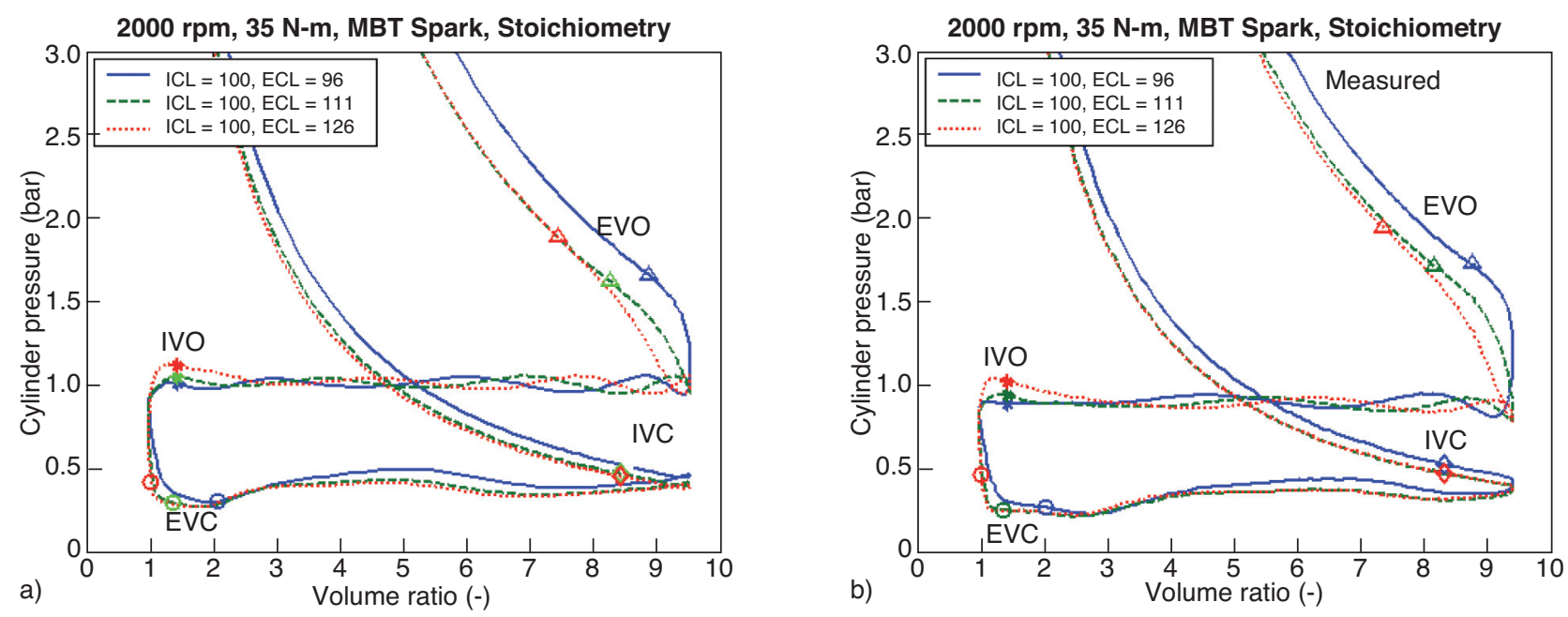

Figure 5

Comparison of high-fidelity simulation results and experimental measurements - engine $P-V$ diagrams with three different exhaust camshaft positions: (a) high-fidelity simulation results; (b) experimental measurements.

optimal value of exhaust camshaft position. Early exhaust valve opening $(\mathrm{EVO})$ reduces expansion stroke length and expansion work. In addition, advancing exhaust timing and closing exhaust valves before TDC results in re-compression of residual gas and larger reverse flow through intake valves. Retarding exhaust timing results in re-induction of exhaust gas when exhaust valve closing (EVC) is substantially after TDC. Both retarding and advancing exhaust timing lead to larger residual fraction, less fresh charge and reduced torque output. Consequently, the optimal tradeoff is achieved in between, at roughly $E C L=116 \mathrm{deg}$. before TDC. Although the effects of exhaust camshaft position on engine torque seem negligible at $2000 \mathrm{rpm}$, they can be more significant at higher speeds due to relatively larger benefits of longer expansion and reduced impact of reinduction of exhaust.

Engine part load operation is explored in Figure 7, showing complete maps of relevant engine parameters obtained when intake and exhaust cam timings are allowed to vary within the complete cam-phasing range. Engine operates at $2000 \mathrm{rpm}, 35 \mathrm{~N}-\mathrm{m}$ of torque, with $F / A$ equivalence ratio (Phi) of one and fixed spark timing. The brake specific fuel consumption (BSFC) contours are plotted in Figure 7a, and residual gas fraction in the cylinder is shown in Figure $7 \mathrm{~b}$. The minimum BSFC point is in the lower left corner of Figure $7 \mathrm{a}$. This is where the valve overlap and the residual gas fraction are maximized. Increased internal exhaust gas recirculation (EGR) requires higher average intake manifold absolute pressure (MAP) for desired torque level and hence leads to reduced pumping losses.
Another local minimum of BSFC is observed at the lower right corner of Figure 7a, where both exhaust and intake cam timings are retarded. The main effect responsible for this is late IVC causing a significant fraction of intake gas to be pushed back from the cylinder into the intake manifold. Again, MAP has to be raised to meet the torque requirement

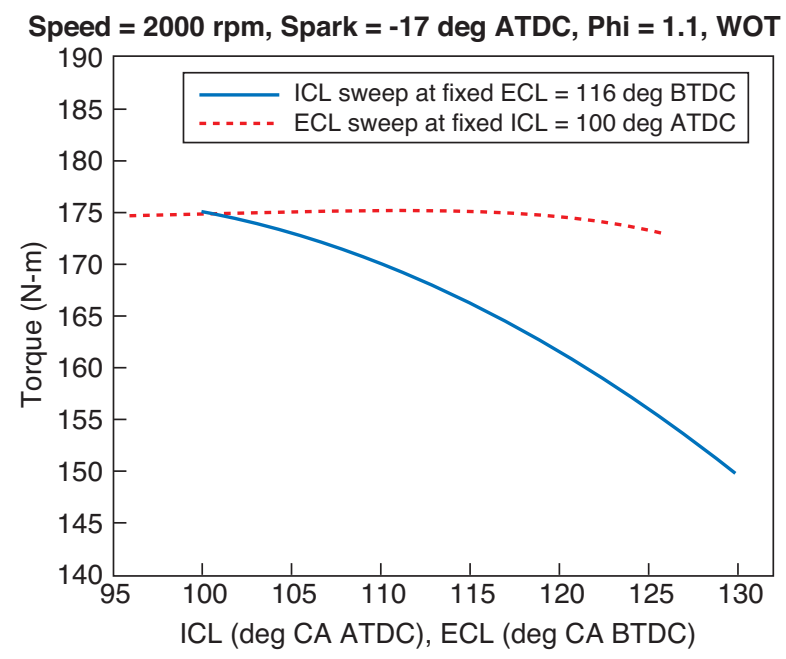

Figure 6

Sensitivity of engine torque to variations of intake (solid line) and exhaust phasing (dotted line). 

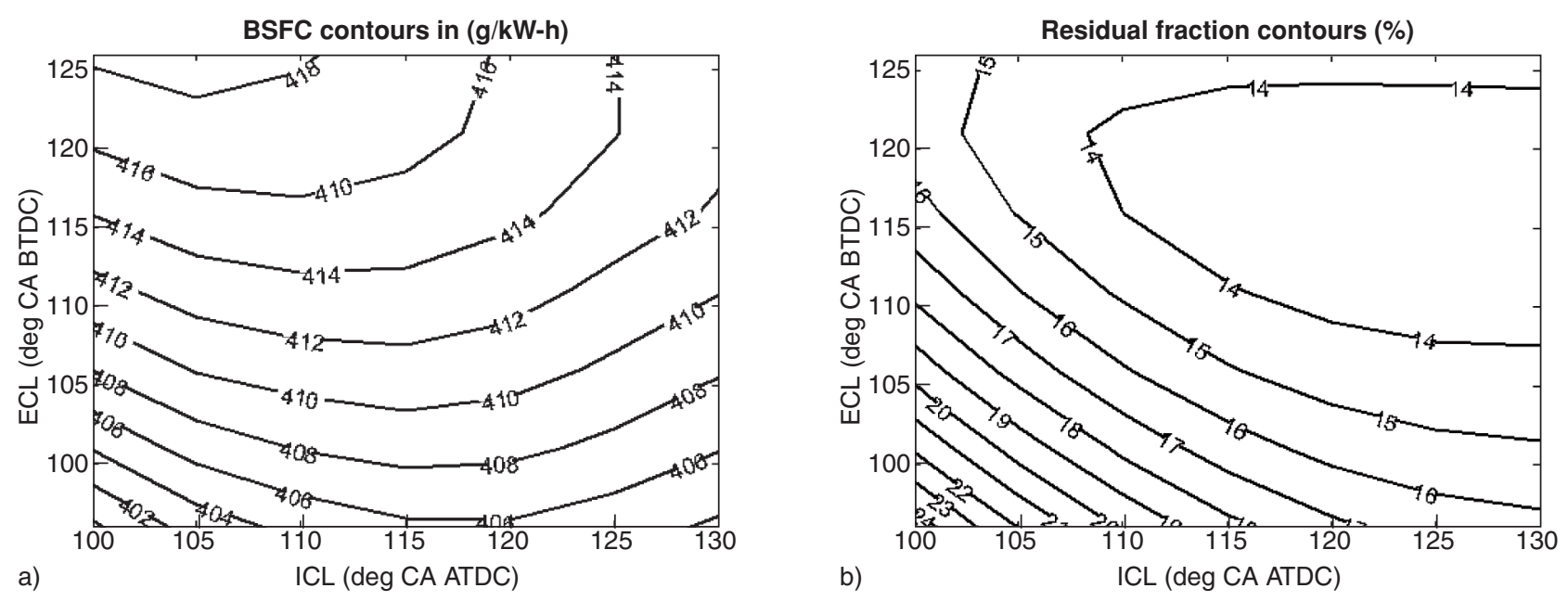

Figure 7

High-fidelity simulation predictions of cam phasing effects on: (a) brake specific fuel consumption; and (b) residual fraction (35 N-m, 2000 rpm, Spark 20 deg BTDC, Phi =1).

and pumping losses are reduced. In addition, the expansion work is increased due to late EVO. The existence of two local BSFC minima indicates that a global optimum may shift abruptly from $I C L_{\min }$ to $I C L_{\max }$ when operating conditions change. Examination of NOx predictions showed a strong correlation with residual fraction. Residual gas lowers combustion temperature and reduces NOx generation. Therefore, conditions corresponding to maximum residual fraction produce the least NOx.

\section{ANN SURROGATE MODELS}

The VVT engine has five independent actuators, namely the throttle, intake cam-phaser, exhaust cam-phaser, spark and fuel injector. Engine speed is an additional input required to determine any engine output. However, to facilitate exhaust aftertreatment with a three-way-catalyst (TWC), the air fuel ratio at part load is normally fixed at stoichiometry. Therefore, the fuel injection pulse width at every point is determined by the mass of trapped air at IVC. In case of WOT operation, this constraint is removed and fuel-air equivalence ratio becomes an additional independent variable. Ranges of all independent variables are given in Table 2. To avoid extrapolation, the ranges covered by training samples extend beyond what is expected in practical situations.

The ANN surrogate models are trained on a set of highfidelity simulation results. A Design of Experiments algorithm - Latin Hypercube Sampling (LHS) [43, 44] - is used to choose a representative set of operating points for generat- ing training samples. Assuming uniform distribution of independent variables, the operating points selected with LHS method populate the entire operating space evenly. Highfidelity simulations are carried out for a set of 2000 operating points at Part Load and 1025 points at WOT. Majority of data are subsequently used for ANN training, while 5\% of points are randomly selected for testing of ANNs. The complete process is illustrated in Figure 8. In a general case, either the simulation or experiments could be used to generate data for training, assuming that the hardware prototype exists. However, high-fidelity simulation was used here due to advantages discussed in the section on Overall Methodology.

The procedure for determining the optimal structure of an ANN model has been developed in previous studies [28, 42]. Networks with one, two and three hidden layers are trained first. The number of neurons in hidden layers is increased gradually until the decreasing rate of the mean squared error

TABLE 2

Ranges of input data used for ANN training

\begin{tabular}{|c|c|c|c|}
\hline Variable & Lower bound & Upper bound & Unit \\
\hline$I C L$ & 95 & 135 & deg ATDC \\
\hline$E C L$ & 91 & 131 & deg BTDC \\
\hline Spark & -60 & 10 & deg ATDC \\
\hline$P H I^{W O T}$ & 1 & 1.5 & - \\
\hline Torque $e^{\text {PartLoad }}$ & -40 & 175 & $\mathrm{~N}-\mathrm{m}$ \\
\hline Speed & 600 & 6500 & $\mathrm{rpm}$ \\
\hline
\end{tabular}




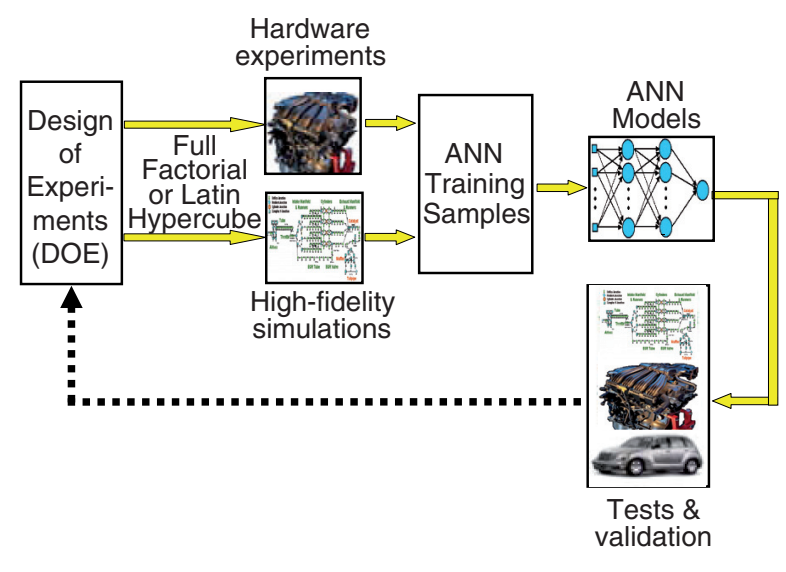

Figure 8

Process of generating engine ANN surrogate models.

(mse) diminishes. The mse of training samples is used to measure fitting accuracy, and the mse of testing samples is used to evaluate generalization accuracy, i.e. accuracy in zones away from training points. The network that attains small training and testing $m s e$, close to the point of diminishing returns, with no signs of overfitting, is selected as the preferred network. Training ANNs using Bayesian Regularization technique, available in MATLAB ${ }^{\circledR}$ Neural Network Toolbox [45], minimizes the risk of overfitting. Comparison of ANN predictions and high-fidelity simulation benchmarks provides a qualitative verification of good ANN behavior without overfitting. It should be noted that using simulation results for training reduces the risk of ANN overfitting, since there is no noise in the data.

Table 3 lists the structure of the preferred networks for all ANN surrogate models used in this work. The network structure is represented by a series of numbers. The first and last numbers represent the number of inputs and outputs, respectively. Each numbers in the middle represents the number of hidden neurons in a corresponding hidden layer.

The fidelity of ANN surrogate models is verified by comparing the predictions of ANN models with high-fidelity simulation output. Figures 9 and 10 illustrate excellent agreement of both WOT and part load results. Peak torque predictions as a function of ICL and ECL are given in Figure 9, and fuel flow rate for $35 \mathrm{~N}-\mathrm{m}, 2000 \mathrm{rpm}$ are shown in Figure 10. In particular, the shape of surfaces and the locations of minima are aligned precisely in high-fidelity simulation benchmarks and ANN predictions.
TABLE 3

Preferred structure of ANN models

\begin{tabular}{l|c|c}
\hline ANN model & Unit & Network structure \\
\hline Fuel flow rate & $\mathrm{g} / \mathrm{s}$ & $5-15-15-1$ \\
\hline NO $x$ emission rate & $\mathrm{g} / \mathrm{s}$ & $5-15-15-1$ \\
\hline Torque & $\mathrm{N}-\mathrm{m}$ & $5-10-10-1$ \\
\hline Residual fraction $^{\text {Wot }}$ & - & $5-15-15-1$ \\
\hline Knock intensity WOT & $\%$ (unburned mixture) & $5-11-11-1$ \\
\hline Knock intensity ${ }^{\text {PartLoad }}$ & $\%$ (unburned mixture) & $5-10-10-10-1$ \\
\hline Exhaust temperature $^{\text {WOT }}$ & $\mathrm{K}$ & $5-11-11-1$ \\
\hline Exhaust temperature $^{\text {PartLoad }}$ & $\mathrm{K}$ & $5-15-15-1$ \\
\hline Combustion duration & degree & $5-12-12-1$ \\
\hline
\end{tabular}

\section{MAXIMIZING ENGINE PERFORMANCE}

In the case of maximum driver demand or WOT, the optimization objective is to maximize torque generation. The constraints are set by the exhaust temperature limit, prevention of knock and physical ranges for independent variables. The constraint on exhaust temperature is introduced to protect the catalyst from overheating. Thus, the optimization problem is formulated as follows [18]:

$$
\begin{aligned}
& \text { Maximize: } \text { Obj }=\text { Torque }(x ; \text { Speed }) \\
& x=(I C L, E C L, \text { Spark,Phi }) \\
& \text { Subject to: } \\
& 100 \leq I C L \leq 130 \text { degree ATDC } \\
& 96 \leq E C L \leq 126 \text { degree BTDC } \\
& -50 \leq \text { Spark } \leq 0 \text { degree ATDC } \\
& 1.0 \leq \text { Phi } \leq 1.3 \\
& T_{e x h}(x ; \text { Speed }) \leq 850^{\circ} \mathrm{C} \\
& K_{i}(x ; \text { Speed }) \leq 0.1
\end{aligned}
$$

where $T_{e x h}$ is exhaust temperature; $K_{i}$ is knock intensity; and $x$ represents four independent variables. Engine speed is regarded as an input parameter determined by the engine/vehicle interaction.

In Equation (1), Torque, $T_{e x h}$, and $K_{i}$ are functions of independent variables and $R P M$, represented by separate ANNs. The optimization framework is setup using fmincon from the Matlab $^{\mathrm{TM}}$ Optimization Toolbox to perform a constrained nonlinear optimization of a multivariable function. The optimization problem is solved at 100 equally spaced steps between 1000 and $6000 \mathrm{rpm}$, and results are shown in Figure 11. While all four variables display a clear trend in the most of the speed range, ECL and Phi show an undesirable sharp fluctuation around $2000 \mathrm{rpm}$. This is mainly due to the insensitivity of engine torque with respect to $E C L$ and Phi, e.g. gradients along the $E C L$ axis in Figure 6 are very small 


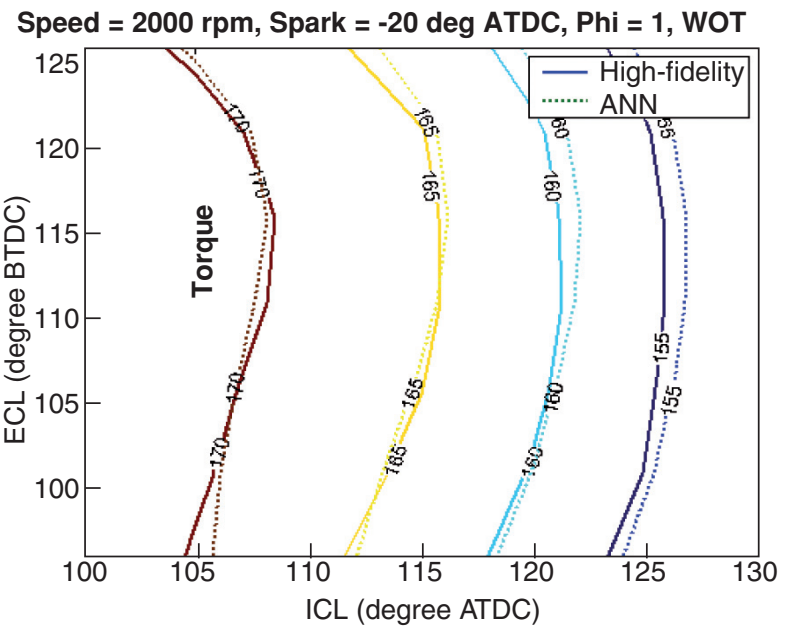

Figure 9

Comparing ANN predictions with high-fidelity simulation benchmarks to validate ANN models: WOT torque $(\mathrm{N}-\mathrm{m})$.
$35 \mathrm{~N}-\mathrm{m}, 2000 \mathrm{rpm}$, Spark $=\mathbf{- 2 0}$ degree ATDC

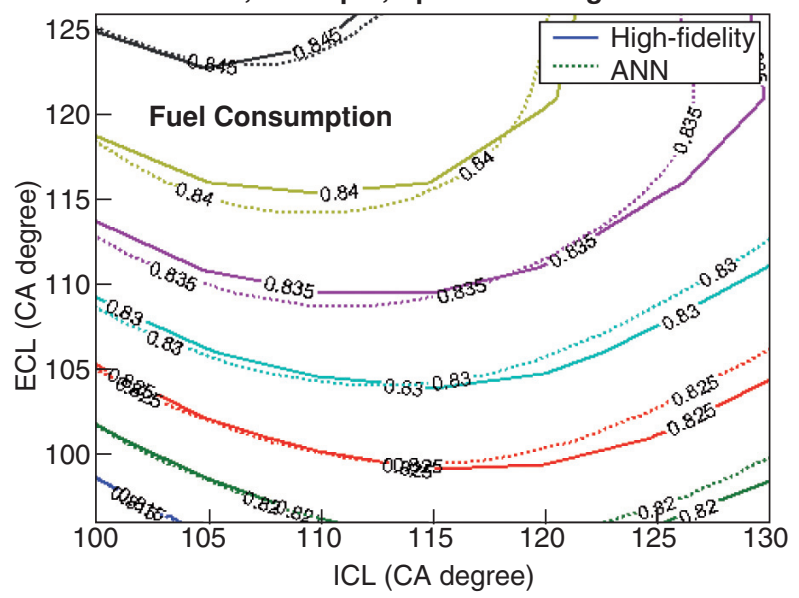

Figure 10

Comparing ANN predictions with high-fidelity simulation benchmarks to validate ANN models: fuel flow rate $(\mathrm{g} / \mathrm{s})$. in the vicinity of the peak torque. To overcome the problem, two extra terms are added to penalize sudden changes of $E C L$ and $P h i$ between two adjacent speed steps. The optimization objective is revised as follows:

$$
\begin{aligned}
\operatorname{Obj}_{k}= & \text { Torque }\left(x ; \text { Speed }_{k}\right)+ \\
& C_{1}\left|E C L_{k}-E C L_{k \pm 1}\right|+C_{2}\left|P h i_{k}-P h i_{k \pm 1}\right|
\end{aligned}
$$

where subscript $k$ indicates the index in a speed sequence. Depending on whether the optimization problems are solved in ascending or descending order of speed, the sign in the penalty terms can be either "-" or "+". We solve the optimization problems in both directions and report the average in Figure 11 with solid lines. Constants $C_{1}$ and $C_{2}$ are adjusted to generate smooth $E C L$ and $P h i$ without a noticeable torque penalty.
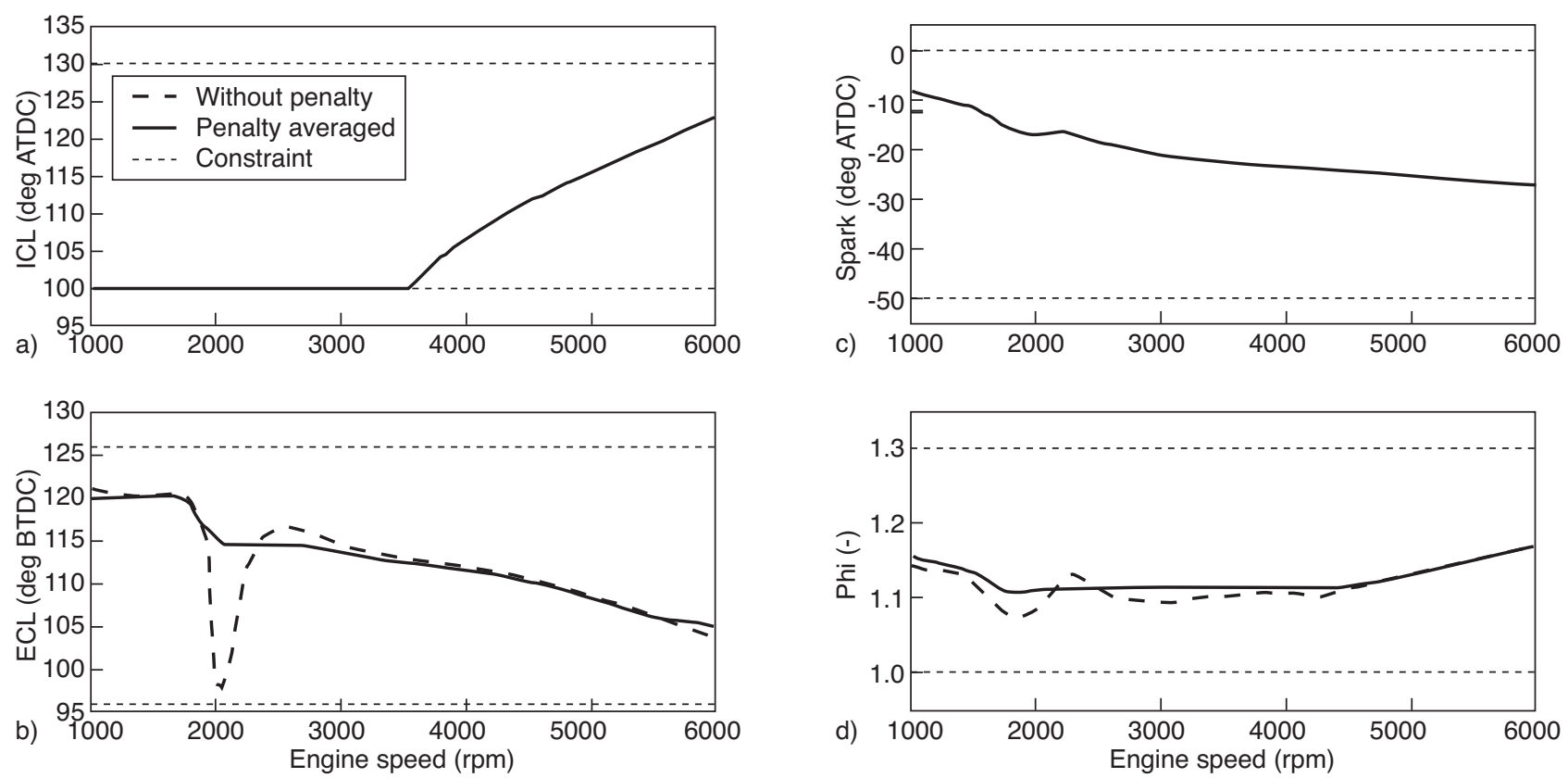

Figure 11

Independent variables optimized for maximum output: (a) $I C L$; (b) $E C L$; (c) Spark timing; and (d) $F / A$ equivalence. 


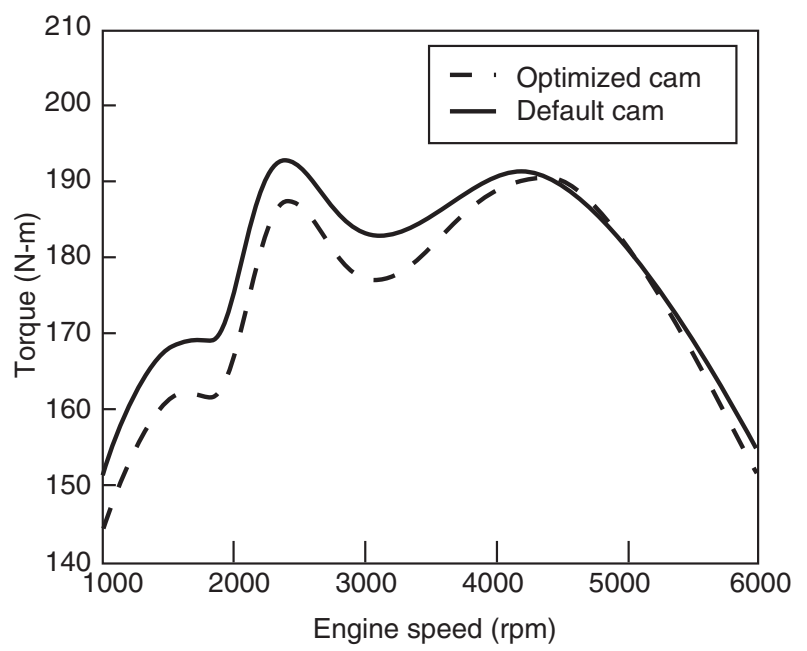

Figure 12

Peak torque improvement due to optimized cam phasing.

Figure 11a indicates significant benefits of advancing $I C L$ at lower engine speeds. Indeed, Figure 12 shows maximum torque improvements between 5\% and $10 \%$ in the $1000-3500 \mathrm{rpm}$ range when compared to the fixed-cam baseline engine. Since $I C L$ is at the lower limit in this range, relaxing of the limit or redesigning of the cam profile could bring additional improvements. Examination of other constraints showed that knock intensity is active at low speeds (up to $2800 \mathrm{rpm}$ ), while maximum exhaust temperature becomes active above $4500 \mathrm{rpm}$.

The optimality of the camshaft positions was validated with experiments in the test cell. Complete sweeps of $I C L$ and $E C L$ were performed while keeping engine speed, spark timing and $A / F$ ratio constant. Tests were performed at three engine speeds: 1200,2000 and 3600 rpm and results are displayed in Figure 13. The optimum ICL and ECL positions are marked with vertical solid bars. The optimized positions coincide with, or are extremely close to the best positions suggested by the experimental curves, and this effectively verifies the optimality.

\section{MINIMIZING FUEL CONSUMPTION AT PART LOAD}

During most driving the engine is operating at part load and fuel economy is the priority. At part load, the fuel-air equivalence ratio is kept at stoichiometric to enable efficient operation of the three-way catalyst. Therefore, minimizing the fuel consumption without considering emission constraints is discussed first. Since engine-out emission can be a concern given the ultra-low tailpipe emissions mandated by current and future regulations, an approach for including emissions into the optimization is discussed in the subsequent section
Given the torque request by the driver and current engine speed, the optimization problem is formulated as follows:

$$
\begin{aligned}
& \text { Minimize } O b j=\dot{m}_{\text {fuel }}(x ; \text { Speed }, \text { Torque }) \\
& x=(I C L, E C L, \text { Spark })
\end{aligned}
$$

Subject to:

$100 \leq I C L \leq 130$ degree ATDC

$96 \leq E C L \leq 126$ degree BTDC

$-60 \leq$ Spark $\leq 10$ degree ATDC

$T_{e x h} \leq 900^{\circ} \mathrm{C}$

$t_{0-50 \%} \leq 60$ degree

$K_{i} \leq 10 \%$ (unburned mass)
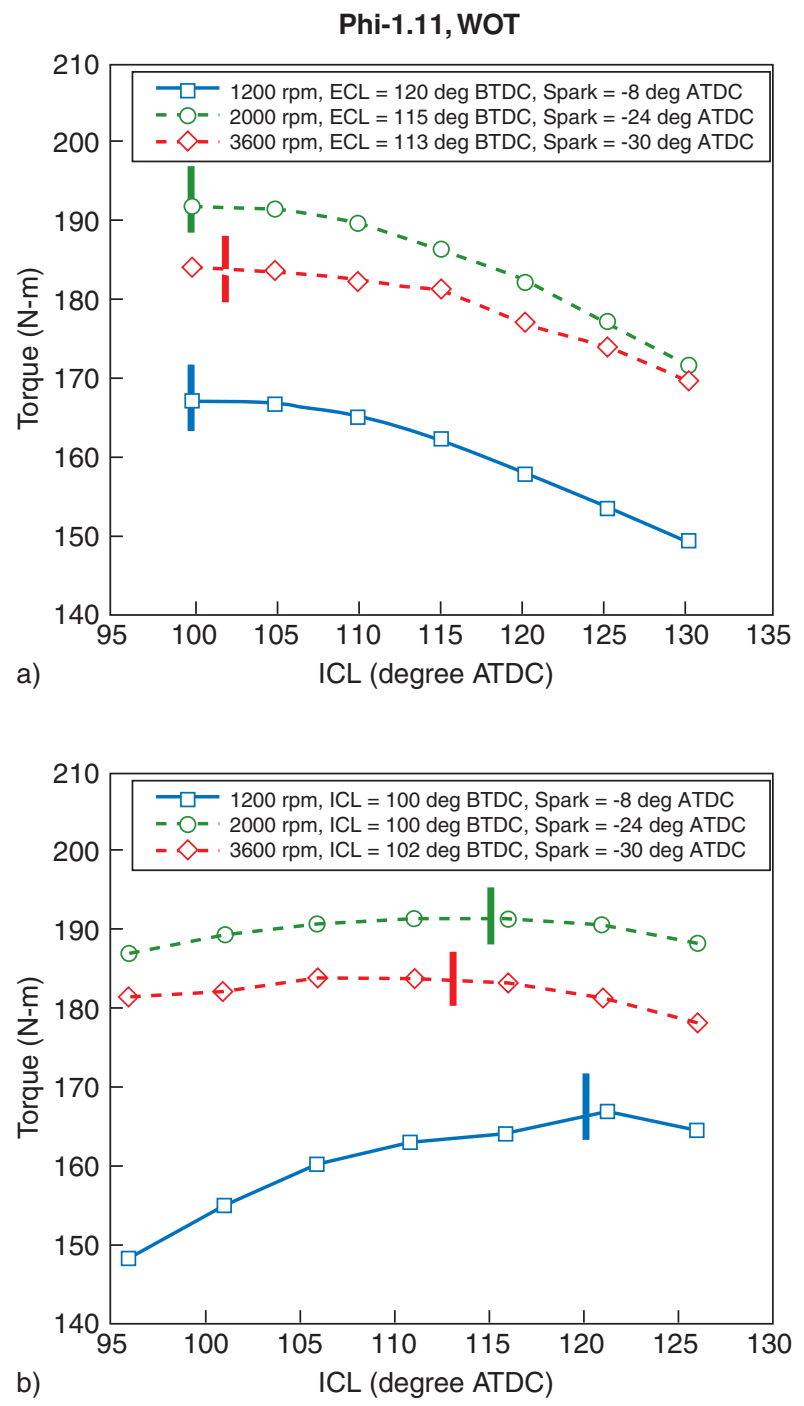

Figure 13

Experimental validation of the optimality of cam positions: (a) intake cam-phasing sweep; (b) exhaust cam-phasing sweep. Optimized camshaft positions are marked with thick solid bars. 
In the above equation, $\dot{m}_{f u e l}$ represents fuel flow rate, and $X$ are independent variables, such as ICL, ECL and Spark timing. All three independent control variables are constrained by corresponding upper and lower limits. The constraint on $T_{\text {exh }}$ protects catalyst from overheating. An interval between ignition and phasing of the 50\% mass burned point $\left(t_{0-50 \%}\right)$ is checked to avoid extremely slow burning and incomplete combustion. Knock intensity $\left(K_{i}\right)$ is defined as the mass fraction of unburned mixture when auto-ignition happens, and more than $10 \%$ is deemed unacceptable to prevent possible damage to the engine or excessive noise. The ANN models listed in Table 3 are used to evaluate independent variables within the optimization framework.

The optimization problem is solved on a $50 \times 20$ grid of engine speed and torque. Along each grid line of fixed engine speed, optimization is carried out in sequence from high torque to low torque. To facilitate optimization, the results obtained at one grid node are used as the initial values for optimization at the next grid node. Multiple initial values are used for the first node on each grid line. Computational efficiency of ANN surrogate models enables solving a total of 1000 optimization problems within four hours on a desktop personal computer.

The results of optimized $I C L, E C L$ are plotted in Figures 14a and b. As shown in Figure 14a, the optimal ICL changes suddenly from being most advanced to being most retarded when increasing either engine speed or load from the low speed and low load quadrant. The discontinuity is the consequence of the abrupt transition from one local minimum point to the other one identified in Figure 7a. For a similar reason, an additional discontinuity occurs when approaching the high speed and high load corner. This time, the optimal ICL reverts to being most advanced. In contrast, the optimal $E C L$ surface is smooth, as shown in Figure 14b. Except at high speed and

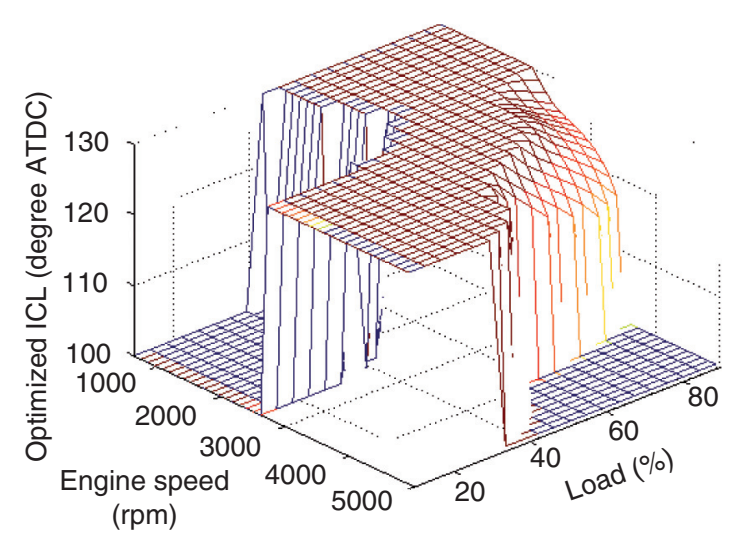

a)

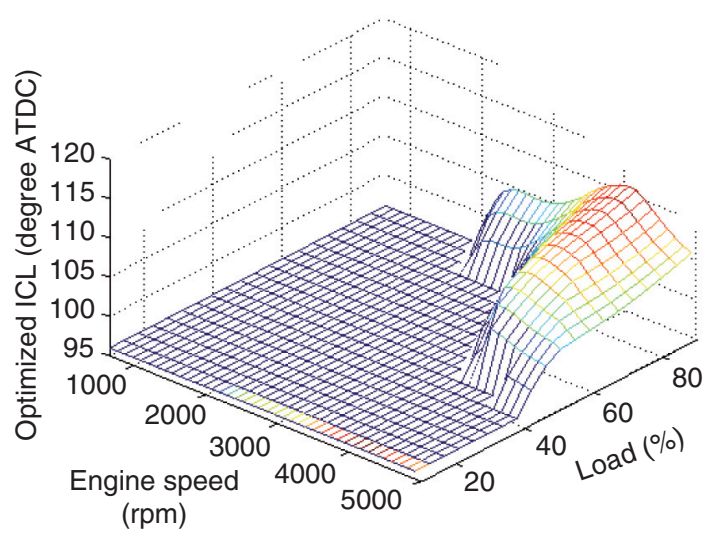

b)

Figure 14

Optimization results for minimizing fuel consumption: (a) intake camshaft position; (b) exhaust camshaft position.

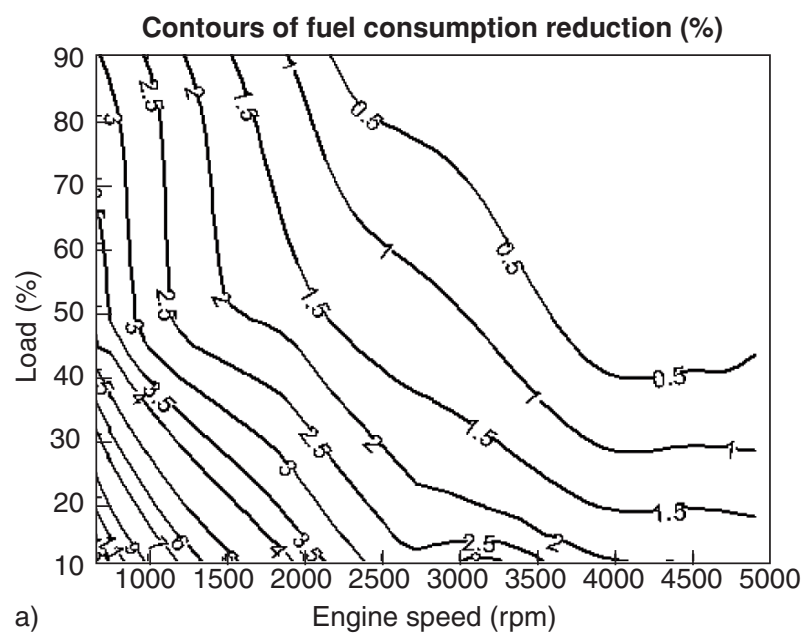

a)

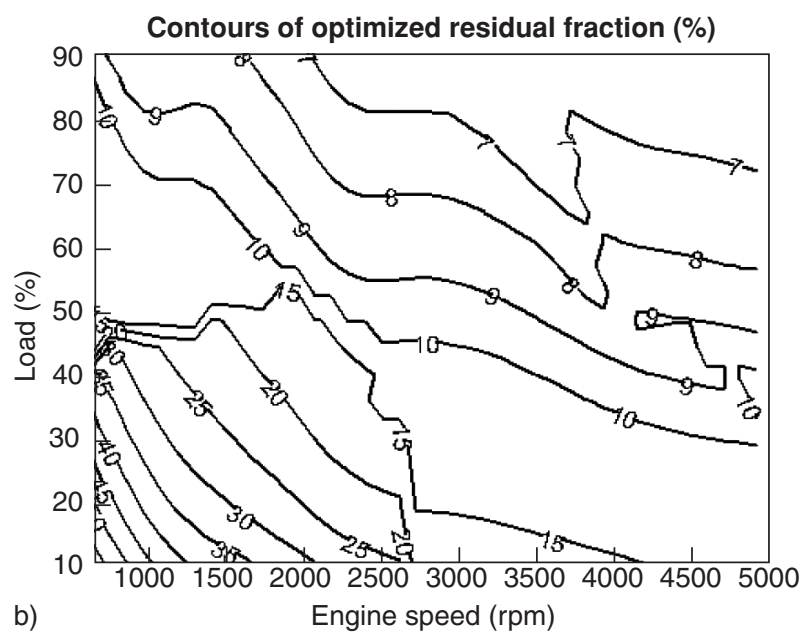

Figure 15

Results of optimizing valve and spark timing for best fuel economy: (a) relative fuel consumption reduction compared to the baseline; and (b) residual fraction in the cylinder. 
load, the exhaust event is retarded to prolong the expansion stroke, thus increasing gross specific work and thermal efficiency. At high speed and load, advancing ECL reduces pumping loss, while the effect of interrupting expansion early becomes less tangible. The optimal ECL surface represents the best compromise between two competing effects.

Figures $15 \mathrm{a}$ and $\mathrm{b}$ show maps of relative fuel consumption reduction compared with the baseline fixed-cam engine, and residual fraction obtained with the optimized ICL, ECL and Spark, respectively. While absolute benefits are highest at higher loads, relative improvements are greater in the low load $(<40 \mathrm{~N}-\mathrm{m})$ and low speed $(<2000 \mathrm{rpm})$ corner, ranging from $4 \%$ to $11 \%$. Figure $15 \mathrm{~b}$ shows that optimal $I C L$ leads to large valve overlap and high residual faction in the low speed/low load corner, which helps reduce engine-out NOx emissions. Indeed, subsequent close inspection of NOx predictions revealed up to eight times lower values of the NOx emission index (g NOx/kg Fuel) in the low-speed, low-load part of the operating range.

\section{CLOSING REMARKS - IMPLEMENTATION AND EMISSIONS ISSUES}

The setpoints obtained in the previous section represent a true optimum with respect to corresponding objectives. However, practical implementation might require additional considerations. As an example, step changes of optimal ICL shown in Figure 14 are not desirable due to potential issues with dynamic actuator control and driveability. Excessive transients might also degrade efficiency and emissions benefits. The engine-out emissions constraint might need to be considered as well. In both cases realistic driving schedules have to be analyzed in order to enable refinement of the optimal setpoint maps. The essence of the approach is discussed here, but details are omitted for brevity and can be found in [31].

Distribution of engine operating time over a set of representative driving schedules provides a foundation for global refinement of the VVA engine's calibration. If the goal is to make transients smother, slopes of surfaces in actuator maps should be limited in a way that causes the least impact on real-world fuel economy. This is achieved by moving the modified points in the direction of less frequently visited regions [31]. If emissions are considered, the total driving time can be broken up and lumped into a limited number of representative operating points. Then, the NOx penalty term is included in the objective function in order to investigate the trade-off between fuel economy and NOx emission. Subsequently, the optimization problem can be formulated in a way that enables minimizing fuel consumption while constraining total NOx emissions below the given target value [31].

In summary, our study is focused on the core calibration problem, i.e. determining actuator set-points for an engine operating in typical driving conditions. Special issues, such as cold start and idle roughness should be treated separately, just like in the case of fixed-cam engines. Depending on the design of cam-phasers, parasitic losses associated with actuation can be a factor at near-idle conditions. This should be accounted for in the model or examined experimentally after the final refinement of component design. The outcome will determine whether the optimal strategy will be applied in a complete speed range, or adjustments will be needed to offset the impact of parasitic losses.

\section{CONCLUSIONS}

This work proposes a systematic methodology for characterizing the behavior of a high-degree of freedom engine and developing efficient calibration methods for handling increased number of independent variables. The approach uses a multi-variable optimization framework for determining the best combination of actuator set-points for any operating condition. The methodology is simulation based, and it relies on two key enablers: (i) high-fidelity simulation capable of predicting complex interactions in the high degree-offreedom engine; and (ii) artificial neural networks suitable for computationally intensive optimization runs.

The methodology is generic and can be applied to engine/powertrain system with a large number of independent variables. A case study demonstrates its application to a multi-cylinder spark-ignition engine with dual-independent cam phasing. The study addresses optimization of camshaft positions, spark timing and $F / A$ ratio for maximum torque output at WOT and minimum fuel consumption at part load. The optimization problem is solved individually at many operating points covering the complete operating range. Important constraints, such as knock, exhaust temperature and excessive combustion duration (indication of incomplete combustion and misfires) are included in the algorithm.

Practical implementation might require post-optimality processing of optimized results to smooth discontinuities in the intake camshaft phasing map and account for phenomena that may have not been modeled. NOx emissions could be included in the optimization formulation as well. Since emissions are regulated over a complete driving schedule, a promising approach is to determine relevant operating points through analysis of driving schedules and add a NOx penalty term in the optimization objective.

\section{ACKNOWLEDGEMENTS}

The authors appreciate the contribution of Roger Vick, Fadi Kanafani, Michael Prucka, Eugenio DiValentin, of DaimlerChrysler in developing the component modules for the engine simulation tool and other technical support. 


\section{REFERENCES}

1 Ahmad, T. and Theobald, M.A. (1989) A survey of variablevalve-actuation technology. SAE Technical Paper No. 891674.

2 Hannibal, W., Flierl, R., Stiegler, L. and Meyer, R. (2004) Overview of Current Continuously Variable Valve Lift Systems for Four-Stoke Spark-Ignition Engines and the Criteria for Their Design Ratings. SAE Technical Paper No. 2004-01-1263.

3 Flierl, R. and Fluting, M. (2000) The Third Generation of Valvetrains - New Fully Variable Valvetrains for Throttle-Free Load Control. SAE Technical Paper No. 2000-01-1227.

4 Nakamura, M., Hara, S., Yamada, Y., Takeda, K., Okamoto, N. and Hibi, T. (2001) A Continuous Variable Valve Event and Lift Control Device (VEL) for Automotive Engines. SAE Technical Paper No. 2001-01-0244.

5 Nishizawa, K., Mitsuishi, S., Mori, K. and Yamamoto, S. (2001) Development of Second Generation of Gasline P-ZEV Technology. SAE Technical Paper No. 2001-01-1310.

6 Hong, H., Parvate-Patil, G.B. and Gordon, B. (2004) Review and Analysis of Variable Valve Timing Strategies-Eight Ways to Approach. Proceedings of the Institution of Mechanical Engineers, Part D. J.Automobile Eng., 218, 1179-1200.

7 Gray, C. (1988) A review of variable engine valve timing. SAE Technical Paper No. 880386.

8 Dresner, T. and Barkan, P. (1989) A review of variable valve timing benefits and modes of operation. SAE Technical Paper No. 891676.

9 Asmus, T.W. (1991) Perspectives on applications of variable valve timing. SAE Technical Paper No. 910445.

$10 \mathrm{Ma}$, T.H. (1988) Effect of variable engine valve timing on fuel economy. SAE Technical Paper No. 880390.

11 Bohac, S. and Assanis, D. (2004) Effects of Exhaust Valve Timing on Gasoline Engine Performance and Hydrocarbon Emissions. SAE Technical Paper No. 2004-01-3058.

12 Roepke, K. and Fischer, M. (2001) Efficient Layout and Calibration of Variable Valve Trains. SAE Technical Paper 2001-01-0668.

13 Flint, S. and Causey, P. (2003) Use of Experimental Design and Two Stage Modeling in Calibration Generation for Variable Camshaft Timing Engines, Design of Experiments (DOE), in der Motorenentwicklung, Expert Verlag, ISBN 3-8169-2271-6, pp.57-77.

14 Morton, T., Connors, R., Maloney, P. and Sampson, D. (2003) Model-Based Optimal Calibration of a Dual Independent Variable Valve-Timing Engine, Design of Experiments (DOE), in der Motorenentwicklung, Expert Verlag, ISBN 3-8169-22716 , pp. 77-85.

15 Rask, E. and Sellnau, M. (2004) Simulation-Based Engine Calibration: Tools, Techniques, and Applications. SAE Technical Paper No. 2004-01-1264.

16 Fu, H., Chen, X., Mustafa, E., Trigui, N., Richardson, S. and Shilling, I. (2004) Analytical Investigation of Cam Strategies for SI Engine Part-Load Operation. SAE Technical Paper No. 200401-0997.

17 Kramer, U. and Philips, P. (2002) Phasing Strategy for an Engine with Twin Variable Cam Timing. SAE Technical Paper No. 2002-01-1101.

$18 \mathrm{Wu}$, B., Prucka, R.G., Filipi, Z.S., Kramer, D.M. and Ohl, G.L. (2005) Cam-Phasing Optimization Using Artificial Neural Networks as Surrogate Models - Maximizing Torque Output. SAE Technical Paper No. 2005-01-3757. SAE Trans. - J. Engines.
19 Mehrotra, K., Mohan, C.K., Ranka, S. (1997) Elements of Artificial Neural Networks, the MIT Press, Cambridge, Massachusetts, ISBN 0-262-13328-8.

$20 \mathrm{He}$, Y. and Rutland, C.J. (2002) Modeling of a Turbocharged DI Diesel Engine Using Artificial Neural Networks. SAE Technical Paper No. 2002-01-2772.

$21 \mathrm{He}$, Y. and Rutland, C.J. (2004) Application of Artificial Neural Networks in Engine Modeling. Int. J. Engine Res., 5, 4, 281-296.

22 Brahma, I. and Rutland, C.J. (2003) Optimization of Diesel Engine Operating Parameters Using Neural Networks. SAE Technical Paper No. 2003-01-3228.

23 Grimaldi, C.N. and Mariani, F. (1997) On-board Diagnosis of Internal Combustion Engines: a New Model Definition and Experimental Validation. SAE Technical Paper No. 970211.

24 Grimaldi, C.N. and Mariani, F. (2001) OBD Engine Fault Detection Using a Neural Approach. SAE Technical Paper No. 2001-01-0559.

25 Krug, C., Liebl, J., Munk, F., Kammer, A. and Reuss, H.-C. (2004) Physical Modelling and Use of Modern System Identification for Real-Time Simulation of Spark Ignition Engines in All Phases of Engine Development. SAE Technical Paper No. 2004-01-0421.

26 Winsel, T., Ayeb, M., Theuerkauf, H.J., Pischinger, S., Schernus, C. and Lutkemeyer, G. (2004) HiL-Calibration of SI Engine Cold Start and Warm-up Using Neural Real-Time Model. SAE Technical Paper No. 2004-01-1362.

27 Ayeb, M., Lichtenthäler, D., Winsel, T. and Theuerkauf, H.J. (1998) SI engine modeling using neural networks. SAE Technical Paper No. 980790.

$28 \mathrm{Wu}$, B., Filipi, Z.S., Assanis, D.A., Kramer, D.M., Ohl, G.L., Prucka, M.J. and DiValentin, E. (2004) Using artificial neural networks for representing the air flow rate through a 2.4 liter VVT engine. SAE Technical Paper No. 2004-01-3054. SAE Trans. - J. Engines.

29 Hornik, K., Stinchcombe, M., and White, H. (1989) Multilayer feedforward networks are universal approximators. Neural Networks, 2, 5, 359-366.

30 Hornik, K. (1991) Approximation capabilities of multilayer feedforward networks. Neural Networks, 4, 2, 251-257.

31 Wu, B., Filipi, Z.S., Prucka, R.G., Kramer, D.M. and Ohl, G.L. (2006) Cam-phasing Optimization Using Artificial Neural Networks as Surrogate Model - Fuel Consumption and NOx Emissions, SAE paper 2006-01-1512. SAE Trans., J. Engines, presented at the 2006 SAE World Congress in Detroit.

32 WAVE V5 Engine Reference Manual (2002) Ricardo Software, Ricardo, Inc., November.

33 Morel, T., Flemming, M. and LaPointe, L.A. (1990) Characterization of Manifold Dynamics in the Chrysler 2.21 S.I. Engine by Measurements and Simulation. SAE Technical Paper No. 900679.

34 Wren, C.S. and Johnson, O. (1995) Gas Dynamics Simulation for the Design of Intake and Exhaust Systems - Latest Techniques. SAE Technical Paper No. 951367.

35 Millo, F., Ferraro, C.V. and Pilo, L. (2000) A Contribution to Engine and Vehicle Performance Prediction. SAE Technical Paper No. 2000-01-1266.

36 Filipi, Z., and Assanis, D.N. (1991) Quasi-dimensional computer simulation of the turbocharged spark-ignition engine and its use for 2- and 4-valve engine matching studies. SAE Technical Paper No. 910075. SAE Trans., 100, Sect. 3.

37 Filipi, Z. (1994) Investigation of Variable Valve Area Strategies for a Turbocharged SI-Engine. Proceedings of the IMechE 5th International Conference on Turbocharging and Turbochargers, London, pp. 93-102. 
38 Filipi, Z.S. and Assanis, D.N. (2000) The Effect of Stroke-toBore Ratio on Combustion, Heat Transfer and Performance of a Homogeneous-Charge Spark-Ignited Engine of Given Displacement. Int. J. Engine Res., 1, 2, JER0500, London, 191208.

39 Tabaczynski, R.J., Trinker, F.H. and Shannon, B.A. (1980) Further refinement and validation of a turbulent flame propagation model for spark-ignition engines. Combust. Flame, 39, 2, $111-121$

40 Poulos, S.G. and Heywood, J.B. (1983) The effect of chamber geometry on spark-ignition engine combustion. SAE Technical Paper No. 830334.

41 Ho, S.Y. and Kuo, T. (1997) A Hydrocarbon Autoignition Model for Knocking Combustion in SI Engines. SAE Technical Paper No. 971672.

42 Wu, B., Filipi, Z., Kramer, D.M., Ohl, G.L., Prucka, M.J. and DiValentin, E. (2005) Using Neural Networks to Compensate Altitude Effects on the Air Flow Rate in Variable Valve Timing Engines. SAE Technical Paper No. 2005-01-0066. SAE Trans. J. Engines.
43 McKay, M.D., Beckman, R.J. and Conover, W.J. (1979) A comparison of three methods for selecting values of input variables in the analysis of output from a computer code. Technometrics, 21, 2, 239-245.

44 Lunani, M., Sudjianto, A. and Johnson, P.L. (1995) Generating efficient training samples for neural networks using Latin Hypercube sampling. Proceedings of the 1995 Artificial Neural Networks in Engineering (ANNIE'95), St. Louis, MO, USA, Nov. 12-15, pp. 209-214.

45 Demuth, H. and Beale, M. (2002) Neural Network Toolbox User's Guide (Version 4), Mathworks Inc.

46 Rublewski, M.J. and Heywood, J.B. (2001) Modeling No Formation in Spark Ignition Engines With a Layered Adiabatic Core and Combustion Inefficiency Routine. SAE Technical paper No. 2001-01-1011.

Final manuscript received in October 2006 or distributed for profit or commercial advantage and that copies bear this notice and the full citation on the first page. Copyrights for components of this work owned by others than IFP must be honored. Abstracting with credit is permitted. To copy otherwise, to republish, to post on servers, or to redistribute to lists, requires prior specific permission and/or a fee: Request permission from Documentation, Institut français du pétrole, fax. +33147527078 , or revueogst@ifp.fr. 